\title{
Comparison between palonosetron and ramosetron to prevent postoperative nausea and vomiting in patients undergoing laparoscopic surgery
}

\author{
Patel Vaibhavi B ${ }^{1, *}$, Patel Kiran B ${ }^{2}$, Mehta Vikram P', Agarwal Sameermohan ${ }^{4}$, Patel Hardik $\mathbf{G}^{5}$ \\ ${ }^{1}$ Tutor, ${ }^{2,3}$ Assistant Professor, ${ }^{4,5}$ Resident, ${ }^{1,2,4,5}$ Dept. of Anaesthesia, ${ }^{3}$ Dept. of Surgery, B.J. Medical College, Ahmedabad, \\ Gujarat, India
}

*Corresponding Author:

Email: drvaibhavipatel@ outlook.com

Received: $8^{\text {th }}$ December, 2017

Accepted: $12^{\text {th }}$ February, 2018

\begin{abstract}
Introduction and Aims: Postoperative nausea and vomiting (PONV) are very common and distressing adverse events after general anaesthesia. Palonosetron and ramosetron are newer, second generation, selective 5-HT3 receptor antagonists. The present study was carried out to compare the efficacy and safety of palonosetron and ramosetron for prevention of postoperative nausea and vomiting (PONV) over the period of 72 hours in patients undergoing for laparoscopic surgery under general anaesthesia.

Materials and Methods: 80 patients of ASA class I and II undergoing for various laparoscopic surgeries were randomly allocated into 2 groups of 40 each, to receive Inj. palonosetron $75 \mu \mathrm{g}$ (group P) or Inj. Ramosetron $0.3 \mathrm{mg}$ (group R). Patients were monitored for emesis, severity of nausea, requirement of rescue antiemetic and complete response up to 72 hours $(0-6,6-24,24-72)$ post operatively.

Results: During 0-6 hours, severity of PONV was comparable in both drug groups but during 24-72 hours, PONV score 2 was observed in $5 \%$ and $17.5 \%$ of patients of group $\mathrm{P}$ and group $\mathrm{R}$ respectively ( $\mathrm{p}=0.027$ ). While score 3 was observed in $15 \%$ of patients of group $\mathrm{R}$ and none of the patients of group $\mathrm{P}(\mathrm{p}=0.01)$. On comparison of complete response between Group $\mathrm{P}$ and Group $\mathrm{R}$, at 0-6 hours response was almost equal but during 6-24 hours and 24-72 hours number of patient having complete response were more in Group P (97.5\% and 82.5\%) as compared to Group R (65\% and 57\% respectively).

Conclusion: Palonosetron given as a prophylaxis for post-operative nausea and vomiting (PONV) in patients undergoing for laparoscopic surgeries seems to have better antiemetic effect over ramosetron.
\end{abstract}

Keywords: PONV, Palonosetron, Ramosetron, Laparoscopic surgery.

\section{Introduction}

Postoperative nausea and vomiting (PONV) are very common and distressing adverse events after general anaesthesia. Various gynaecological surgeries, middle ear surgeries, ophthalmic surgeries, laparoscopic surgeries are now a days carried out on 'day care' basis, for which PONV is a significant problem. The general incidence of PONV is about $30 \%$ to $50 \%$ and can go up to $80 \%$ in subsets of high-risk patients. ${ }^{1}$ Risk factors for PONV are both anaesthesia related and non-anaesthesia related. The anaesthesia related risk factors for PONV include use of volatile anaesthetics and opioid for postoperative analgesics. ${ }^{2}$ Non-anaesthesia related risk factors for PONV include female sex, history of PONV/ motion sickness, being a non-smoker, and younger age, ${ }^{3}$ surgical procedures like laparoscopy. During laparoscopic surgeries higher chances of PONV are due to increased intraabdominal pressure and volume by carbon dioxide insufflation, hypercarbia, aspiration of gastric contents, extreme position of patient. ${ }^{4,5} \mathrm{PONV}$ is commonly associated with serious post-surgical complications like wound dehiscence, surgical site bleeding which leads to unexpected prolong hospital stay, delayed recovery, high patient dissatisfaction and delay in return to work. ${ }^{6,7}$ It is easier to prevent than to treat PONV. Several antiemetics of different pharmacological classes are available to prevent PONV in patients scheduled for elective surgery which include anticholinergic, antihistamines, phenothiazines, butyrophenones and selective 5-hydroxytryptamine-3 (5-HT3) receptor antagonists (ondansetron, granisetron, palonosetron, ramosetron, dolasetron). ${ }^{8}$ Despite the well-known shared mechanism of action of 5-HT3 receptor antagonists, they have their own distinguished chemical structures, variable receptor binding affinities, durations of action and have lesser adverse effects than other antiemetics.

Among the 5HT3 receptor antagonists $1^{\text {st }}$ generation of drug is ondansetron (having half-life of 3-4 hours). Palonosetron and ramosetron are newer, second generation, potent, selective 5-HT3 receptor antagonists having a strong receptor binding affinity and a long elimination half-life and a long duration of action..$^{9,10}$ They have been recently approved for prophylaxis against PONV. ${ }^{11}$ Our study is a single blinded observational type of study comparing antiemetic properties and side effects of palonosetron $(75 \mu \mathrm{g}$ iv) with ramosetron (0.3 $\mathrm{mg}$ iv).

\section{Materials and Methods}

This study was carried out on randomly selected 80 patients of either sex from the age group 18-60 years (weight $>50 \mathrm{~kg}$ ) of ASA risk I and II undergoing for various laparoscopic surgical procedures. We decided sample size by taking $95 \%$ confidence interval and $20 \%$ allowable error, as per the previous study which found 
complete response to be $83.33 \%$ for palanosetron group. Thus, the sample size was 20 in both groups. Considering this we decided 40 patients in each group. ${ }^{12}$ The aim of our study was to compare the efficacy and safety of palonosetron and ramosetron for prevention of postoperative nausea and vomiting (PONV) over the period of 72 hours in patients undergoing for laparoscopic surgery under general anaesthesia. Ethical clearance was obtained from the ethical committee of our institution. Patients were pre-operatively assessed a day before the surgery and patients with history of motion sickness, past history of PONV, pregnant female, menstruating female, patients undergone anaesthesia in last 24 hours and BMI >35 were excluded. Patient's physical and systemic examination was done and routine laboratory investigations like haemoglobin, total WBC count, random blood sugar, renal function test, serum electrolytes, serum bilirubin, X-rays and ECG were advised and reports recorded. Written and informed consent was taken after explaining the patients about the procedure. Patients were not given any solid or liquid food after $10 \mathrm{pm}$ on the previous night before operation. The patients were randomly divided into 2 groups, receiving Inj. Palonosetron $75 \mu \mathrm{g}$ IV diluted in $5 \mathrm{ml}$ saline(group P) or receiving Inj. Ramosetron $0.3 \mathrm{mg}$ iv diluted in $5 \mathrm{ml}$ saline (group R). Randomization was done by random number table generated in computer to assign the type of the drug to patient. After taking the patient on the OT table, IV line was secured, monitors in form of ECG, pulse oximeter and NIBP were applied. Inj. Glycopyrrolate $(0.004 \mathrm{mg} / \mathrm{kg})$ and Inj. Fentanyl (2 $\mu \mathrm{g} / \mathrm{kg}$ ) were given as premedication. The study drug was administered according to the group just before induction of anaesthesia. The person injecting the study drug was not involved further in observation, so patient and observer both were kept unaware about the drug injected. After pre-oxygenated with $100 \% \mathrm{O}_{2}$ for 3 mins, patients were induced with Inj. Thiopentone Sodium 5-6 $\mathrm{mg} / \mathrm{kg}$ and intubation was facilitated using Inj. Scoline $2 \mathrm{mg} / \mathrm{kg}$. Anaesthesia was maintained with $\mathrm{O}_{2}+\mathrm{N}_{2} \mathrm{O}+$ sevoflurane with controlled ventilation using closed circuit. Vecuronium Bromide $(0.08 \mathrm{mg} / \mathrm{kg})$ was used as non-depolarizing muscle relaxant. Intra-operative vitals were monitored and documented. Intravenous fluids were administered as per requirement of the patient. Inj. Diclofenac Sodium $(1.5 \mathrm{mg} / \mathrm{kg})$ IV was given as an analgesic at the end of surgery. After completion of surgery, neuromuscular blockade was reversed with Inj. lycopyrrolate $(0.008 \mathrm{mg} / \mathrm{kg})$ and Inj. Neostigmine $(0.05 \mathrm{mg} / \mathrm{kg})$ IV. After through oropharyngeal and endotracheal suctioning, patients were extubated. Patients were monitored for vital signs, emetic episodes, severity of nausea, requirement of rescue antiemetic, and adverse effect of drug up to 72 hours $(0-6,6-24,24-$ $72 \mathrm{hrs}$ ) post operatively, which began after the patient responded to a vocal command postoperatively. As a "rescue" antiemetic, Ondansetron 4mg IV was given, if $\geq 2$ episodes occurred within 72 hours post operatively and the time of its administration was noted. Oral feeding was started almost after 7-8 hours of surgery depending upon return of peristalsis (confirmed by surgeon). Adverse events like rash, headache, diarrhoea within 72 hours of surgery were assessed and noted. Nausea is a sensation of unease and discomfort in the upper stomach with an involuntary urge to vomit which may or may not precede vomiting. Vomiting is expulsion of stomach contents through the mouth. Retching is an involuntary attempt to vomit that do not produce stomach contents. Complete response is neither PONV nor administration of rescue antiemetic medication in postoperative period. Nausea and vomiting were evaluated over a period up to 72 hours (0-6, 6-24, 24-72 hours) post operatively using PONV score(0-complete response, 1-nausea, 2-nausea and vomiting, 3-requirement of rescue antiemetics) and 4 point verbal descriptive scale for nausea (0-no nausea, 1-mild nausea, 2-moderate nausea, 3-severe nausea). We collected datas in terms of percentage of patients having PONV score, nausea VDS score, complete response, and requirement of rescue antiemetic. For statistical analysis, we used Microsoft Excell-07 and Epi-Info-7.0 software. Data obtained from the study groups was statistically analysed using the chi square test across different time periods of assessment. All values are displayed as mean and $\%$ of patients. $\mathrm{P}$ value $<0.05$ was considered significant.

\section{Results}

Our study was a single blinded observational type of study carried out on 80 patients of ASA class I and II undergoing for various laparoscopic surgeries under general anaesthesia. Our 2 study groups were similar in regards to patient demographic data (age, sex, weight, BMI), duration of anaesthesia. We selected patients undergoing for different laparoscopic surgeries as per Table 1.

Table 1: Type of surgery

\begin{tabular}{|l|c|c|}
\hline Type of surgery & Group P & Group R \\
\hline Lap cholecystectomy & 17 & 18 \\
\hline Lap appendicectomy & 8 & 6 \\
\hline Diagnostic laparoscopy & 12 & 13 \\
\hline $\begin{array}{l}\text { Diagnostic laparoscopy and } \\
\text { ovarian cystectomy }\end{array}$ & 1 & 2 \\
\hline Laparoscopic fundoplication & 2 & 1 \\
\hline
\end{tabular}


Table 2: PONV score

\begin{tabular}{|c|c|c|c|c|c|c|}
\hline \multirow[t]{2}{*}{ Time } & \multirow[t]{2}{*}{ Group } & \multicolumn{4}{|c|}{ Number. of patients having [n\%] } & \multirow[t]{2}{*}{ P value } \\
\hline & & Score 0 & Score 1 & Score 2 & Score 3 & \\
\hline \multirow[b]{2}{*}{ 0-6 Hours } & $\mathrm{P}$ & $39(97.5 \%)$ & $1(2.5 \%)$ & $0(0)$ & $0(0)$ & \multirow{2}{*}{0.55} \\
\hline & $\mathrm{R}$ & $38(95 \%)$ & $2(5 \%)$ & $0(0)$ & $0(0)$ & \\
\hline \multirow[b]{2}{*}{ 6-24 Hours } & $\mathrm{P}$ & $39(97.5 \%)$ & $1(2.5 \%)$ & $0(0)$ & $0(0)$ & \multirow[b]{2}{*}{0.027} \\
\hline & $\mathrm{R}$ & $26(65 \%)$ & $6(15 \%)$ & $6(15 \%)$ & $2(5 \%)$ & \\
\hline \multirow[b]{2}{*}{ 24-72 Hours } & $\mathrm{P}$ & $33(82.5 \%)$ & $5(12.5 \%)$ & $2(5 \%)$ & $0(0)$ & \multirow[b]{2}{*}{0.01} \\
\hline & $\mathrm{R}$ & $23(57 \%)$ & $4(10 \%)$ & $7(17.5 \%)$ & $6(15 \%)$ & \\
\hline
\end{tabular}

During 0-6 hours, severity of PONV was comparable in group P and Group R. While during 6-24 hours and 24-72 hours the severity of PONV was significantly higher in group $\mathrm{R}$ as compared to group $\mathrm{P}(\mathrm{p}=0.027$ and $\mathrm{p}=0.01$ respectively $)$.

Table 3: 4 point verbal descriptive scale (VDS) for Nausea

\begin{tabular}{|l|c|c|c|c|c|c|}
\hline \multicolumn{1}{|c|}{ Time } & Group & \multicolumn{3}{|c|}{ Number. of patients having } & P value \\
\hline & & $\begin{array}{c}\text { Grade 0 } \\
{[\mathbf{N}(\boldsymbol{\%})]}\end{array}$ & $\begin{array}{c}\text { Grade 1 } \\
{[\mathbf{N}(\%)]}\end{array}$ & $\begin{array}{c}\text { Grade 2 } \\
{[\mathbf{\%}(\%)]}\end{array}$ & $\begin{array}{c}\text { Grade 3 } \\
{[\mathbf{N}(\%)]}\end{array}$ & \\
\hline \multirow{2}{*}{$0-6$ hours } & $\mathrm{P}$ & $39(97.5 \%)$ & $0(0 \%)$ & $1(2.5 \%)$ & $0(0 \%)$ & \multirow{2}{*}{0.05} \\
\cline { 2 - 6 } & $\mathrm{R}$ & $36(90 \%)$ & $2(5 \%)$ & $2(5 \%)$ & $0(0 \%)$ & \\
\hline \multirow{2}{*}{$\begin{array}{l}6-24 \\
\text { hours }\end{array}$} & $\mathrm{P}$ & $38(95 \%)$ & $0(0 \%)$ & $2(5 \%)$ & $0(0 \%)$ & \multirow{2}{*}{0.07} \\
\cline { 2 - 6 } $\begin{array}{l}24-72 \\
\text { hours }\end{array}$ & $\mathrm{R}$ & $27(67.5 \%)$ & $6(15 \%)$ & $5(12.5 \%)$ & $2(5 \%)$ & \\
\cline { 2 - 6 } & $\mathrm{P}$ & $38(95 \%)$ & $0(0 \%)$ & $1(2.5 \%)$ & $1(2.5 \%)$ & \multirow{2}{*}{0.003} \\
\hline
\end{tabular}

No statistically significant difference was found in severity of nausea in both the study groups during 0-6 and 6-24 hours. But during 24-72 hours nausea was more severe in group $\mathrm{R}$ as compared to group $\mathrm{P}(\mathrm{p}=0.003)$.

Table 4: Requirement of rescue anti-emetic

\begin{tabular}{|l|c|c|c|}
\hline Group & 0-6 Hours & 6-24 Hours & 24-72 Hours \\
\hline Group P & $0(0 \%)$ & $1(2.5 \%)$ & $0(0 \%)$ \\
\hline Group R & $0(0 \%)$ & $2(5 \%)$ & $6(15 \%)$ \\
\hline
\end{tabular}

For requirement of rescue antiemetic during 0-6 hours and 6-24 hours, there was no significant difference in Group P and Group R. But during 24-72 hours requirement of rescue antiemetic in Group $\mathrm{R}$ was $15 \%$, while in Group P it was nil. Even after administration of rescue medication, patient was included in further study because we have observed that in group $\mathrm{P}, 1$ patient required rescue drug during 6-24 hours but he didn't require any drug during 24-72 hours. While in group R, 2 patients required rescue drug in 6-24 hours and also during 24-72 hours along with 4 new patients who required rescue drug during $24-72$ hours (total 6 patients).

Table 5: Comparison of complete response (depends only on PONV Score)

\begin{tabular}{|l|c|c|c|}
\hline Group & $\begin{array}{c}\text { Complete response } \\
(\mathbf{0 - 6} \text { hours) }\end{array}$ & $\begin{array}{c}\text { Complete response } \\
(\mathbf{6 - 2 4} \text { hours })\end{array}$ & $\begin{array}{c}\text { Complete response } \\
(\mathbf{2 4 - 7 2} \text { hours })\end{array}$ \\
\hline Group P & $39(97.5 \%)$ & $39(97.5 \%)$ & $33(82.5 \%)$ \\
\hline Group R & $38(95 \%)$ & $26(65 \%)$ & $23(57 \%)$ \\
\hline
\end{tabular}

On comparison of complete response between Group P and Group R, at 0-6 hours response was almost equal but during 6-24 hours and 24-72 hours number of patient having complete response were more in Group $\mathrm{P}$ as compare to Group R. As definition of complete response is no PONV, no requirement of rescue antiemetic. We have interpreteted table 5 depending only on PONV Score not on VDS Score.

\section{Discussion}

PONV is a significant problem in the general population in modern anaesthesia practice. Reported incidence of PONV ranges from 30 to $80 \%$ within the first 24 hours after laparoscopic surgery when no any prophylactic antiemetic is given. ${ }^{13-15}$ If high-risk patients are considered as a separate group, then as much as $70 \%$ of these patients will experience PONV. PONV leads to adverse consequences such dehydration, electrolyte imbalance, aspiration of vomitus, surgical complication like wound dehiscence, bleeding beneath skin flaps, loss of vitreous fluid following intraocular surgery, delayed recovery, delayed return to work of ambulatory patients, extended hospital stay, unplanned admissions and associated expenses. The high incidence of PONV during first 24 hours of laparoscopic surgery may be explained by central action of $\mathrm{CO}_{2}$, stretching of 
peritoneum and diaphragm, increase in blood pressure, use of opioid analgesia and intraoperative use of $\mathrm{N}_{2} \mathrm{O} .{ }^{16}$ All these factors are considered to provoke nausea and vomiting by reducing blood flow and releasing emetogenic substances like serotonin. ${ }^{17,18}$ Vomiting is a reflex process regulated by vomiting centre which is situated in a dorsal part of lateral reticular formation of the medulla lying ventral to solitary tract and its nucleus. Peripheral stimulation of chemoreceptors and mechanoreceptors in the stomach, gut, liver and peritoneum activate the vomiting centre via vagus nerve. Vestibular and psychogenic factors affect the vomiting centre by means of afferent routes from the labyrinth and the higher cortical centres respectively. The vomiting centre stimulates diaphragm (via phrenic nerve), striated muscle tissue of the abdominal wall and thorax (via spinal nerves) and the muscle tissue of the stomach, oesophagus, larynx, and pharynx (via vagus nerve). This stimulation leads to retching sensation and/or vomiting. In multiple surveys, patients list the avoidance of nausea and vomiting as their number one concern when faced with surgery and anaesthesia. So prevention of PONV in surgical patients should be given equal priority to that of post-operative pain control. ${ }^{19} \mathrm{~A} \mathrm{~J}$ Wilson and Candiotti $\mathrm{K}$ A administered study drug before induction of anaesthesia. ${ }^{20,21}$ In our study, we had also administered drug before induction of anaesthesia as described previously.

Palonosetron is a "second generation" 5HT3receptor antagonist which has the highest binding affinity to the 5-HT3 receptor and elimination half-life is as long as 40 hours. Palonosetron shows avid binding to the 5-HT3 receptor, with a $\mathrm{pKi}$ of 10.4 which far exceeds other 5-HT3 antagonists. This binding affinity is 100 times more than that of ondansetron. The chemical structure is dissimilar to serotonin, so palonosetron may bind to the 5-HT3 receptor at an allosteric site, different to other antagonists that bind at the orthosteric site occupied by serotonin. This interaction at the allosteric site may prevent attachment of serotonin at its orthosteric site, explaining the insurmountable binding noted in vitro. $^{22}$ Furthermore studies of calcium influx in specimens exposed to and then washed clear of palonosetron show continued receptor occupation well beyond that predicted by controls and far in excess of that shown by ondansetron. Ramosetron Hydrochloride showed 5-HT3 receptor antagonistic effects on serotonin-induced contraction of guinea pig colon. Vomiting induced by injection of cisplatin (chemotherapy induced vomiting) was inhibited by administration of ramosetron prior to onset of vomiting or after initial development of vomiting. It is a carbazalone derivative that is structurally related to serotonin and possesses specific serotonin receptor antagonist properties which act by blocking 5-HT3 receptor present in afferent vagal nerve ending of GI mucosa. ${ }^{23}$ Elimination half-life of ramosetron is 9.3 hours. It has higher affinity $(\mathrm{Ki}=0.091)$ and slower dissociation rate for 5HT3 receptors as compared to other antagonists. $^{24}$

In our study incidence of complete response during 0-6 hours postoperatively, in group $\mathrm{P}$ was $97.5 \%$ and group $\mathrm{R}$ was $95 \%$. The incidence of complete response during 6-24 hours was $97.5 \%$ in group $\mathrm{P}$ and was $65 \%$ in group R (Table 5). As per study done by Ahluwalia and et el, complete response was observed in $92.73 \%$ and $80 \%$ of the patients during 0-2 hours and 2-24 hours respectively in Group $\mathrm{P}$ while in Group $\mathrm{R}$ it $90.91 \%$ and $70.91 \%$ within the same time frame ( $\mathrm{p}$ value $>0.05) .{ }^{25} \mathrm{It}$ shows that complete response with palonosetron and ramosetron are comparable in 0-24 hours. Another Study done by Chattopadhyay suman et al to compare effect of palonosetron and ramosetron for prevention of PONV after caesarean section under spinal anaesthesia shows complete response at $0-2$ hours $85.5 \%$ and $83.3 \%$ in Group $\mathrm{P}$ and Group R respectively ( $\mathrm{p}$ value $>0.05$ ), while during 2-24 hours $70.9 \%$ and $53.7 \%$ in Group $\mathrm{P}$ and Group $\mathrm{R}$ respectively(p value $<0.05) .{ }^{26}$ In our study, during 24-72 hours, the incidence of complete response with palonosetron was $82.5 \%$ and with ramosetron was only $57 \%(\mathrm{p}$ value $=0.01)$ which suggest significant difference. As per study done by Ahluwalia and et el, during 24-72 hours, number of patients having complete response were significantly higher in palonosetron group $(72.7 \%)$ as compared to ramosetron group $(52.7 \%)$ having $\mathrm{p}$ value of 0.03 which is significant. Study done by Chattopadhyay et al during 24-48 hours shows complete response at $63.3 \%$ and $44.4 \%$ in Group P and Group $\mathrm{R}$ respectively( $\mathrm{p}$ value $<0.05$ ). So it suggests that during 24-72 hours complete response was significantly higher with palonosetron as compared to ramosetron. Another study done by Gautam Piplai et al shows that, the incidence of a complete response during 0-3 hours in the postoperative period was $90 \%$ with ramosetron and 93.3\% with palonosetron, the incidence during 3-24 hours postoperatively was $86.6 \%$ with ramosetron and $90 \%$ with palonosetron. ${ }^{27}$ During 24-72 hours, the incidence is $60 \%$ and $83.3 \%$ respectively. Thus regarding complete response during 0-24 hours in the postoperative period, there was no significant difference between patients who had received ramosetron and those who had received palonosetron $(\mathrm{P}>0.05)$, but during 2472 hours, a complete response was significantly higher in patients of group $\mathrm{P}$ than in patients of group $\mathrm{R}(\mathrm{P}<0.05)$. Thus results of this study are comparable with our study.

In our study, nausea severity according to verbal descriptive scale (VDS) at 0-6 hours, none of the patients developed severe nausea in both groups and during 6-24 hours, $5 \%$ of the patients developed severe nausea in both Group P and Group R (Table 3). During 24-72 hours severe nausea was observed in $15 \%$ of the patients with Group $\mathrm{R}$ and $2.5 \%$ of patients in Group $\mathrm{P}$ ( $\mathrm{p}$ value $=$ 0.003 which is significant). A study done by Ahluwalia et el, also shows nausea severity was significantly higher 
in Group R in comparison to Group P during 24-72 hours ( $\mathrm{p}$ value $=0.01)$.

In our study, there was no significant difference in requirement of rescue antiemetic in group $\mathrm{P}$ and group $\mathrm{R}$ during 0-6 and 6-24 hours but during 24-72 hours requirement of rescue antiemetic was $15 \%$ in the patients in Group R as compared to none of the patients in Group $\mathrm{P}$ which is significantly higher (Table 4). Sung Hoon Kim and et al carried out a similar comparative study which demonstrated that, requirement of rescue antiemetic was higher in Group R (34.2\%) as compared to Group P $(11 \%) .{ }^{28}$ According to our study after a single bolus dose of injectable palonosetron and ramosetron, none of our patient developed any side effects. Thus, both of drugs are devoid of clinically important side effects. Thus, during 24-72 hours, palonosetron is more effective than ramosetron for getting complete response. This suggests that antiemetic efficacy of palonosetron lasts longer than ramosetron. A limitation of our study is that, we did not include a placebo control group to evaluate base line incidence of PONV because as per Aspinall and Goodman, if active drugs are available placebo control trials are unethical as PONV itself is a very disturbing and distressing event occurring after laparoscopic surgery. ${ }^{29}$

The exact reason for the difference in effectiveness between palonosetron and ramosetron is not known but may be related to the difference in elimination half-life of drugs, as ramosetron has a half-life of 9 hours while palonosetron has a half-life of 36 hours. The greatest efficacy of palonosetron is due to the fact that its binding affinity to 5HT-3 receptor is 30 times higher than Ramosetron. Palonosetron is unique in term of allosteric interaction with and binding cooperativity to 5HT-3 receptor. ${ }^{30}$ Moreover binding of palonosetron to the receptor and thereby inhibiting calcium influx is not easily reversible suggesting that palonosetron uniquely triggers 5HT- 3 receptor internalization and induces prolong inhibition of receptor function. Kaplan and meier analysis showed that efficacy of palonosetron was higher than ramosetron to prevent postoperative nausea and vomiting. On comparing the efficacy of our 2 drug groups, we can inference that patients in Group P had better rate of complete response and lower rate of nausea and vomiting when assessed using PONV scores and nausea Verbal Descriptive Scale (VDS scale), in comparison to Group R.

\section{Conclusion}

Our study displays that due to longer duration of action, a single dose of PALONOSETRON given before induction of anaesthesia is much more efficient in preventing PONV for up to 72 hours as compared to ramosetron. It seems that palonosetron given in dose of $75 \mu \mathrm{g}$ IV is highly effective and optimal dose to prevent PONV with minimal or almost nil side effects.

So, our study inferences that palonosetron given as a prophylaxis for post-operative nausea and vomiting
(PONV) in patients undergoing for laparoscopic surgeries seems to have better antiemetic effect over ramosetron.

\section{References}

1. Apfel CC, Laara E, Koivuranta M, Greim CA, Roewer N. A simplified risk score for predicting postoperative nausea and vomiting: conclusions from cross-validations between two centres. Anaesthesiology. 1999;91(3):693700.

2. Apfel CC, Heidrich FM. Evidence-based analysis of risk factors for post- operative nausea and vomiting. $\mathrm{Br} \mathrm{J}$ Anaesthesia. 2012;109:742-753.

3. Stoltz R, Cyong JC, Shah A, Parisi S. Pharmacokinetic and safety evaluation of palonosetron, a 5-Ht-3 receptor antagonist, in u.s. and Japanese healthy subjects. J Clin Pharmacol. 2004;44(5):520-31.

4. Watcha MF, White PF. Postoperative nausea and vomiting: its etiology, treatment, and prevention. Anaesthesiology. 1992;77:162-84.

5. Habib AS, Gan TJ. Evidence-based management of postoperative nausea and vomiting: a review. Can J Anaesth. 2004;51:326-41.

6. Muchatuta NA, Paech MJ. Management of postoperative nausea and vomiting: focus on palonosetron. Ther Clin Risk Manag. 2002;5(1):21-34.

7. Gan T J. Risk factors for postoperative nausea and vomiting. Anesth Analg. 2006;102(6):1884-98.

8. Rabasseda X. Ramosetron, a 5-ht3 receptor antagonist for the control of nausea and vomiting. Drugs today. 2002;38:75-86.

9. Wong EH, Clark R, Leung E, Loury D, Bonhaus DW, Jakeman L, Parnes H, Whiting RL, Eglen RM. The interaction of rs 25259-197, a potent and selective antagonist, with 5-ht3 receptors, in vitro. Br J Pharmacol. 1995;114(4):851-9.

10. Kranke P, Eberhart LH. Postoperative nausea and vomiting: rational algorithms for prevention and treatment based on current evidence. Anasthesiol intensivmed notfallmed schmerzther. 2009;44:2869.

11. Boogaerts JG, Vanacker E, Seidel L, Albert A, Bardiau FM.: Assessment of postoperative nausea using a visual analogue scale. Acta Anaesthesiol scand 2000; 44: 470-4.

12. Gan TJ, Diemunsch P, Habib AS, Kovac A, Kranke P, Meyer TA, et al. Consensus guidelines for the management of postoperative nausea and vomiting. Anesth Analg. 2014;118:85-113.

13. Ryu J, So y-m, Hwang J, Do s-h.: Ramosetron versus ondansetron for the prevention of postoperative nausea and vomiting after laparoscopic cholecystectomy. Surg Endosc. 2010;24:8120.

14. Tramurg J. Efficacy, dose-response, and safety of ondansetron in prevention of postoperative nausea and vomiting: a quantitative systematic review of randomized placebo-controlled trials. Anesthesiology. 1997;87:1277.

15. Nesek-adam V, Grizelj-stojcić. Comparison of dexamethasone, metoclopramide, and their combination in the prevention of postoperative nausea and vomiting after laparoscopic cholecystectomy. Surg Endosc. 2007;21:6077.

16. Iitomi $\mathrm{T}$, Toriumi S, Kondo A, Akazawa $\mathrm{T}$, Nakahara $\mathrm{T}$. Incidence of nausea and vomiting after cholecystectomy performed via laparotomy or laparoscopy. Masui. 1995;44(12):1627-31.

17. Leksowski K, Peryga P, Szyca R. Ondansetron, metoclopramid, dexamethason, and their combinations compared for the prevention of postoperative nausea and 
vomiting in patients undergoing laparoscopic cholecystectomy: a prospective randomized study. Surg endosc. 2006;20:8786.

18. Diebel LN, Dulchavsky SA, Wilson RF. Effect of increased intra-abdominal pressure on mesenteric arterial and intestinal mucosal blood flow. J Trauma. 1992;33:4592.

19. Macario A, Weinger M, Carney S, Kim A. Which clinical anesthesia outcomes are important to avoid? The perspective of patients. Anesth Analg. 1999;89:652-8.

20. Siddiqui M A, Scott L J. palonosetron, drugs 2004;64(10):1125-32.

21. Wilson AJ, Diemunsch P, Lindeque BG, Scheinin H, Helbo-hansen HS, Kroeks MV, Kong KL. Single-dose iv Granisetron in the prevention of postoperative nausea and vomiting. Br J Anaesth. 1995;76(4):515-8.

22. Wallenborn J, Kranke P. Palonosetron hydrochloride in the prevention and treatment of postoperative nausea and vomiting. Clinical medicine insights. Therapeutics. 2010;2:387-99.

23. Manning, Cioffi, C.l. Usyatinsky. Novel serotonin type 3 receptor partial agonists for the potential treatment of irritable bowel syndrome. Bioorg Med Chem Lett. 2011;21(1);58-61.

24. Hirata T, Keto Y. Evaluation of the pharmacological profile of ramosetron, a novel therapeutic agent for irritable bowel syndrome. J Pharmacol Sci. 2007;104:263-73.

25. Ahluwalia P, Ahluwalia A. Comparison of ramosetron and palonosetron for prevention of postoperative nausea and vomiting following middle ear surgeries: a prospective randomized double-blind study. IJSS 2015;10:17354/440.

26. Chattopadhyay S, Goswami S. Palonosetron versus ramosetron prophylaxis for control of postoperative nausea and vomiting after caesarean delivery under spinal anaesthesia. The Journal of Obstetrics and Gynecology of India. 2015;65(1):28-33.

27. Piplai G, Chakrabarty I. a comparative study between palonosetron and ramosetron to prevent postoperative nausea and vomiting after laparoscopic cholecystectomy, International Research Journal of Pharmacy and Pharmacology. 2012;2(8):193-197.

28. Kim S, Jeong-yeon H. Palonosetron has superior prophylactic antiemetic efficacy compared with ondansetron or ramosetron in high risk patients undergoing laparoscopic surgery : a prospective randomized, double-blinded study. Korean $J$ Anesthesiology. 2013;64(6):517-523.

29. Aspinall RL, Goodman NW. Denial of effective treatment and poor quality of clinical information in placebo controlled trials of ondansetron for postoperative nausea and vomiting: a review of published trials. $B M J$. 1995;311:8445.

30. Rojas C, Thomas AG, Alt J, Stathis M, Zhang J, Rubenstein EB, et al. Palonosetron triggers 5-ht(3) receptor internalization and causes prolonged inhibition of receptor function. Eur J Pharmacol. 2010;626:193-9.

How to cite this article: Patel VB, Patel KB, Mehta VP. Agarwal S, Patel HG. Comparison between palonosetron and ramosetron to prevent postoperative nausea and vomiting in patients undergoing laparoscopic surgery. Indian $\mathrm{J}$ Clin Anaesth. 2018;5(3):348-353. 